\title{
CORRELATION OF SAFETY PERCEPTIONS AND SAFETY BEHAVIOR IN UNIVERSITY TEACHING LABORATORY
}

\author{
Rahmat N, Nur Annisa F, Muhammad D and Muhammad H \\ Industrial Engineering Department, Faculty of Engineering, Universitas Indonesia, Depok, Indonesia \\ * Corresponding author: R Nurcahyo \\ Email address: rahmat@eng.ui.ac.id
}

\begin{abstract}
Chemicals usage has been reported as the cause of accidents in a laboratory. Those accidents have caused many injuries, even fatality in many sectors, one of which happened in the University Teaching Laboratory. Accidents usually happen because of unsafe behavior, while unsafe behavior is caused by bad safety perceptions. This paper investigates the correlation of perceptions and behavior in University Teaching Laboratory. The result measured by regression analysis to find out the relationship between two variables showed that there is a strong relationship between perceptions and behavior. Therefore, safe behavior can be created through creating good perception.
\end{abstract}

Keywords: Perception, Behavior, Teaching Laboratory, Regression

\section{INTRODUCTION}

Numerous accidents occur related to chemical usage. Bhopal Disaster might be the biggest chemical disaster in history. Happened in 1984, the factory of Union Carbide leaked the poisonous gas (Methyl Isocyanate) to the environment ${ }^{1}$. Thousands of people became victims of this disaster. Many of them died, while others suffered injuries ${ }^{1}$. Not only in the factory like Bhopal Disaster that took place, but there were also many accident cases in University Laboratories. One of them was Texas Tech Laboratory Accident in 2010. Chemical Safety Board (CSB) has released the investigation of this accident where they found out that it was caused by systemic deficiencies in University Safety Management Practices ${ }^{2}$. This accident occurred during the handling of explosive compounds and resulted in serious injuries to graduate students ${ }^{2}$. These examples show that chemicals are very risky to use.

According to Sumadsad and Ruiz, educational institutions need to implement Safety and Health Policies ${ }^{3}$. Olewski and Snakard stated that there is a misconception that process hazards do not exist within laboratories, thus led to a lack of process safety hazard understanding and impacted losses on financial, environmental, and even fatalities ${ }^{4}$. To escape from that paradigm is to accept that safe laboratory operation is the only way to work $^{4}$. Moreover, working and learning in wet academic laboratories involves potential exposure to a wide range of hazards ${ }^{5}$.

Safety education implementation, according to Hill, is neglected because it has been seen as a disjointed set of rules and procedures without organization, and other things are deemed more important and more interesting ${ }^{6}$. No wonder, there were many accidents happened in laboratories. According to Huang, risk perception has a significant correlation with behavior; those who realize the bad consequences would try so hard to avoid unsafe behavior ${ }^{7}$. This research identifies the relationship of safety perceptions and its impact on creating particular safety behavior in University Teaching Laboratory.

Perception is a process when human interprets and organizes certain sensation they received to create $^{8}$. Perception is a holistic experience that is integrated and completed, but this does not copy the exact thought of real-life and this involves mental process. This is caused by external information that affects human condition? .

There are theories that discuss perception on risks, such as Psychometric Paradigm and Cultural Theory ${ }^{10}$. Psychometric Approach has dominated the research area about perception on risks. This approach has an assumption that perception on risk is multidimensional and measurable with a scale that describes unique characteristics of risk source ${ }^{10}$.

Risk itself is defined as a possibility in experiencing injury or loss that has two components: probability and severity ${ }^{11}$. It's a very essential thing to consider perceptions on safety aspects in order to get a better way to manage and solve certain circumstances. According to Şimșekoǵlu et al. (2012), they concluded that perception on risk could be relatively in line with the statistics distribution on accident, especially when the risk source is commonly known on community ${ }^{12}$.

People who perceived that their job is safe, tend to be less involved in an accident compared to 
those who do not have a good perception on their job. They who perceived their workplaces as a safe place reported that they have less stress, anxiety, and these are strongly related to accident ${ }^{13}$.

According to Seo et al. (2015), it is confirmed that safety behavior is directly affected by sincerity, openness, and extroversion and also indirectly affected by stress reactions, safety motivation, and safety knowledge. Moreover, research results showed that antecedents like safety communication and safety training had a significant influence on safety behavior ${ }^{14}$.

Safety behavior research has evaluated different individual factors such as personal characteristics (Cellar et al., 2001; Wallace and Vodanovich, 2003 on Seo et al., 2015) ${ }^{9}$, job stress (Melamed et al., 1989; Steffy et al., 1986 on Seo et al., 2015), self-perceived fatigue (Kristal-Boneh et al., 1996; Spurgeon et al., 1997 on Seo et al., 2015) and organizational factors such as safety culture (Cooper, 2000; Flin et al., 2000; Guldenmund, 2007 on Seo et al., 2015) and safety climate (Felknor et al., 2000; Neal et al., 2000; Siu et al., 2004 on Seo et al., 2015) ${ }^{14}$.

Bronkhorst (2015) made a distinction between two types of individual behavior: safety compliance and safety participation ${ }^{15}$. Safety compliance describes the core activities that need to be carried out by employees to maintain workplace safety (e.g., using patient lifting devices or adhering to incident reporting procedures) while safety participation refers to behaviors that do not directly contribute to an individual's personal safety, but which do help to develop an environment that supports safety (e.g., addressing physically dangerous behavior or offering a listening ear to co-workers) ${ }^{15}$.

The behavioral component can be defined as the methods regarding safety in the workplace, and the situational component as the policies, procedures, regulations, organizational structures, and management systems related to safety $^{16}$. More than $50 \%$ of safety accidents were caused by human mistakes which were influenced by higher-level organizational problems. Such organizational problems can actually encourage unsafe action. The importance of the organizational factors that can affect personal safety behavior has been emphasized ${ }^{14}$.

Unsafe behavior is defined as any behavior engaged in by an employee without considering safety rules, standards, procedures, instructions, and specified criteria in the system that can negatively influence the system safety or endanger the employee himself or his colleagues ${ }^{17}$. According to this definition, unsafe behavior has a prominent place in occupational accidents, which has been stressed by many studies. Blackmon and Gramopadhye (1995) explained unsafe behavior as a cause of $98 \%$ of accidents. Around $80-90 \%$ of occupational accidents are attributable to unsafe behaviors ${ }^{17}$.

In Health and Safety, there are two commonly used words, hazard and risk. According to HarmsRingdahl (2001), hazard is a source that may cause an incident, and according to International Electrotechnical Commission cited on HarmsRingdahl (2001), hazard is a source or situation which has potential to cause injury or incident. In contrast, risk is a function of probability and consequences $^{18}$.

Based on WHO (2001), Occupational Health and Safety is an activity that is oriented to risk and also defined as cross-function activities which have focus on 1) Health Protection and Promotion, 2) Safety and Health Development and Promotion, 3) Improvement of Physical, Mental, and Social in Society and 4) Enable people to have a productive life socially and economically ${ }^{19}$.

Heinrich (1931) defined sequence model through domino theory in which accident is on the top of the sequence. The more significant contribution from this theory is describing that accidents can be prevented by removing any factors in sequential model ${ }^{20}$.

Recent research in implementing international standards to improve occupational health and safety concludes that those increase not only company's safety perception and behavior but also competitiveness and performances ${ }^{21}$.

\section{METHODS}

This study took place in Universitas Indonesia since it has hundreds of laboratories and many of which involve chemicals for the work. This study investigated some laboratories and focused on students as the research object. First, we formulated the 5-Likert Scale questionnaire which used in the study. It was adopted from the questionnaire in Hayes et al. ${ }^{13}$. The behavior questionnaire was adopted from the Theory of Planned Behavior Manual ${ }^{22}$. Second, before the real survey was conducted, there was validity and reliability test for a pilot survey. The final perceptions questionnaire consists of 49 questions, and the final behavior questionnaire consists of 28 questions. Four hundred eighteen students filled both questionnaires; then, it was processed using SPSS to run the Regression Analysis in order to calculate the correlation between the two variables. 


\section{RESULTS}

\section{Table 1 - Survey result}

\begin{tabular}{lc}
\hline \multicolumn{1}{c}{ Criteria } & Percentage \\
\hline X1 (Perceived Susceptibility) & $61 \%$ \\
X2 (Perceived threats from & $49,5 \%$ \\
environment) & \\
X3 (Perceived threats of & $54 \%$ \\
management) & $65 \%$ \\
X4 (Perceived benefits) & $56 \%$ \\
Y (Safety Behavior) & \\
\hline
\end{tabular}

These all were catagorized into:

- $0 \%-19,99 \%$ = very low

- $20 \%-39,99 \%=$ low

- $40 \%-59,99 \%$ = fair

- $60 \%-79,99 \%=$ good

- $80 \%-100 \%=$ very good

Table 1 shows the percentage from the survey result. Relationship analysis was processed by using a multiple regression test. There were four independent variables and one dependent variable. This test was conducted by using SPSS version 16 and Minitab Version 16.

The next step is the elaboration of the correlation between variables. Every data was converted into binary, where 0 means not good, and 1 means good. To determine each category, we measured the mean score. Categories which were higher than the mean score was categorized into 1 , while the others were 0 . Here's the result of regression analysis:

Table 2 - Regression test result

\begin{tabular}{lccccc}
\hline Variabel & B & T & F & $\begin{array}{c}\text { P- } \\
\text { Value }\end{array}$ & $\begin{array}{c}\text { R-Sq } \\
\text { (Adj) }\end{array}$ \\
\hline X1 & 0,302 & 7,81 & 128,77 & 0,000 & $72,0 \%$ \\
X2 & 0,301 & 6,48 & & & \\
X3 & 0,378 & 7,67 & & & \\
X4 & 0,268 & 6,19 & & & \\
\hline
\end{tabular}

The regression equation was:

$$
\begin{gathered}
y=-0,148+0,302 x_{1}+0,301 x_{2}+0,378 x_{3}+ \\
0,268 x_{4}
\end{gathered}
$$

Based on table 2, T Score was higher than $\mathrm{T}$ Table, and F Score also higher than $\mathrm{F}$ Table. This means that there was a significant relationship between variables and this was also supported by the P-Value 0,000, lower than $\alpha=0,05$, meaning that $x$ and $y$ have a significant relationship. From the result, R2 (adj) was $72 \%$ and this means that this research is quite good based on Walpole et al. $(2013)^{23}$. Safety perceptions significantly impacted safety behavior by $72 \%$, and the rest was impacted by other factors.

\section{DISCUSSION}

The results from the survey show that there are still a number of things that can be improved and relationship test results provide the finding that if there is a good safety perception, there will also be good safety behavior. The perception of safety exists in fair category, so that resulting safety behavior also resides in the same category. This means that if an organization improves safety perception, good safety behavior will also be obtained. To improve safety perception, these are activities that can be done, such as:

- Increase knowledge about Occupational Safety and Health in activities in the laboratory for students.

- Increase knowledge about Occupational Safety and Health in activities in the laboratory for laboratory supervisors.

- Increase student participation in the Occupational Safety and Health application in the Laboratory.

- Improve faculty management support for Occupational Safety and Health in the Laboratory.

- Increase the number of activities that increase awareness of the importance of Occupational Safety and Health in the Laboratory.

Interventions in faculty programs or activities on Occupational Safety and Health as described in the previous chapter are expected to be able to improve perceptions of safety among students. It is because the most frequent user of laboratories is students so that students have a major contribution in preventing work accidents in activities in the laboratory.

\section{CONCLUSION}

The result showed that there was a significant relationship between safety perceptions and safety behavior showed by $p$-value lower than $a$. Based on the result, the regression coefficient (B) is positive, so it can be inferred that improvement in safety perceptions will also improve safety behavior. Safety perception significantly impacted safety behavior by $72 \%$, and the rest was impacted by other factors.

\section{ACKNOWLEDGMENTS}

This work was supported by the HIBAH PIT Q1Q2 under contract number NKB0320/UN2.R3.1/HKP.05.00/2019.

\section{COMPETING INTERESTS}

There is no conflict of interest. 


\section{REFERENCES}

1. Dutta, PK. Bhopal Gas Tragedy: What Had Happened This Day 33 Years Ago That Killed Thousands? 2017. www.indiatoday.in.

2. US Chemical Safety and Hazard Investigation Board CSB Releases Investigation into 2010 Texas Tech Laboratory Accident; Case Study Identifies Systemic Deficiencies in University Safety Management Practices, 2011. www.csb.gov.

3. Sumadsad, CR. \& Jamorabo-Ruiz A. Occupational Safety, Health Conditions and Productivity of Faculty in Education Instututions at The National Capital Region, 2013.

4. Olewski, T. \& Snakard, M. Challenges in Applying Process Safety Management at University Laboratories Journal of Loss Prevention in the Process Industries, 2017; 49: 209-214.

5. Ayi, HR. \& Hon, CY. Safety Culture and Safety Compliance in Academic Laboratories: A Canadian Perspective, 2018.

6. Hill, Jr. \& Robert, H. The Impact of OSHA's Laboratory Standard on Undergraduate Safety Education Journal of Chemical Health and Safety, 2015; 12 17.

7. Huang, YP. Wang, XQ. Ding, RX. \& Xia, NN. Risk Perception, Risk Propensity, and Unsafe Behavior: An Empirical Study of Workers in Chinese Construction Industry, 2016.

8. Pickens, J. Attitudes and Perceptions, 2005.

9. Dunn, AK. \& Stacey, PC. An Introduction to Sensation, Perception, and Attention. In $P$ Banyard $G$, Dillon $C$, Norman and $B$ Winder Essential Psychology, 2014; 93. Los Angeles.

10. Rundmo, T. \& Nordfjærn, T. Does Risk Perception Really Exist? Safety Science Journal, 2017; 230-240.

11. Hussin, MF. \& Wang, B. Industrial Safety Perception Among Post-Graduate Engineering Students Knowledge-Based System 2010; 23: 769-771.

12. Şimșekoǵlu, Ö. Nordfjærn, T. Zavareh, MF. Hezaveh, AM. Mamdoohi, AR. \&
Rundmo, T. Risk Perceptions, Fatalism and Driver Behaviors in Turkey and Iran. Safety Science Journal, 2013; 59: 187192.

13. Hayes, BE. Perander, J. Smecko, T. \& Trask, J. Measuring Perceptions of Workplace Safety-Theoretical and applied implications. Journal of Safety Research.

14. Seo, H. Lee, Y. Kim, J. \& Jee, N. Analyzing Safety Behaviors of Temporary Construction Workers Using Structural Equation Modeling Safety Science, 2015; 77:160-168.

15. Bronkhorst, B. Behaving Safely Under Pressure: The Effects of Job Demands, Resources, and Safety Climate on Employee Physical and Psychosocial Safety Behavior, Journal of Safety Research, 2015; 55: 63-71.

16. Kim, Y. Park, J. \& Park, M. Creating a Culture of Prevention in Occupational Safety and Health Practice. Safety and Health at Work, 2016; 89-96.

17. Mohammadfam, I. Ghasemi, F. Kalatpour, O. \& Moghimbeigi, A. Constructing a Bayesian Network Model for Improving Safety Behavior of Employees at Workplaces, 2017; 35-47.

18. Harms-Ringdahl, L. Safety Analysis, 2001. London.

19. World Health Organization. Occupational Health A Manual for Primary Health Care Workers World Health Organization Regional Office for the Eastern Mediterranean, 2001. Cairo.

20. Sousa, V. Almeida, NM. \& Dias, LA. RiskBased Management of Occupational Safety and Health in The Construction Industry - Part 1: Background Knowledge Safety Science, 2014; 66: 75-86

21. Alfredo, Elfianus, I \& Nurcahyo, R. The Impact of ISO 9001, ISO 14001 and OHSAS 18001 Certification on Manufacturing Industry Operational Performance. Journal of Industrial Engineering and Operations Management, 2018; 18621866.

22. Ni, Y. Cao, Y \& Li, K. Pedestrians' Safety Perception at Signalized Intersections in Shanghai Transportation Research Procedia, 2017; 1955-1963. 
23. Walpole \& Ronald, E. Essentials of Probability and Statistics for Engineers and Scientists, 2013. 